\title{
La gran pena del mundo: apuntes para el estudio de la esclavitud, desde la historia y la literatura cubana
}

\section{The great sorrow of the world: notes for the study of slavery, from a Cuban history and literature perspective}

\author{
Saylí Alba Álvarez*
}

* Profesora de la Universidad de Sancti Spiritus “José Martí Pérez” (Cuba). Es Master en Ciencias de la Educación por la Universidad de Sancti Spíritus. Entre sus publicaciones recientes se encuentran: Claves y Rumbas en Sancti Spiritus, por el CIDMUC; Con el sabor de mi punto, por el Instituto de Investigación Cultural Juan Marinello. Ha recibido los siguientes premios: Beca de Investigación Cultural Samuel Feijoo; Premio Regino Boty y Premio Anual de Investigación Cultural Juan Marinello. Ha participado en gran cantidad de eventos nacionales e internacionales, relacionados con la historia y la cultura. Correo electrónicosaylialba@gmail.com

(1) https://orcid.org/0000-0003-0980-151X

Historial editorial

Recibido: 19-marzo-2020

Aceptado: 15-junio-2020

Publicado: 21-julio-2020

ISSN-e: 2594-2956 
La gran pena del mundo: apuntes para el estudio de la esclavitud, desde la historia y la literatura cubana

\section{Resumen}

El trabajo presentado: La gran pena del mundo: apuntes para el estudio de la esclavitud, desde la historia y la literatura cubana, es una propuesta didáctica que tiene como objetivo, Proponer obras literarias que aborden el tema de la esclavitud desde diferentes perspectivas. $\mathrm{La}$ temática propuesta responde a una problemática social de gran importancia: el legado de las culturas africanas a la consolidación de la nación cubana y por tanto a la identidad y a la cultura. La propuesta se realiza desde una perspectiva interdisciplinar entre la literatura y la historia. Para el estudio se analizaron obras de gran importancia que marcaron pautas en el tratamiento del tema en la literatura universal y se proponen como bibliografía. El trabajo consta de Introducción donde se proponen los antecedentes del estudio teniendo en cuenta los autores más significativos, Desarrollo donde se analizan las obras propuestas y se exponen referencias bibliográficas que abordan el tema, Conclusiones $y$ Bibliografía.

Palabras clave: esclavitud, propuesta, bibliografía, literatura
The great sorrow of the world: notes for the study of slavery, from a Cuban history and literature perspective

\begin{abstract}
The work presented here, The great sorrow of the world: notes for the study of slavery, from a Cuban history and literature perspective, is a didactic proposal that aims to propose literary works that address the issue of slavery from different perspectives. The theme responds to a social problem of great importance: the legacy of African cultures to the consolidation of the Cuban nation and therefore to its identity and culture. The proposal is made from an interdisciplinary perspective between literature and history. For the study, works of great importance that set standards in the treatment of the subject in world literature were analyzed and proposed as a bibliography. The work consists of: Introduction where the background of the study is proposed taking into account the most significant authors, Development where the proposed works are analyzed and bibliographic references that address the subject are exposed, Conclusions and Bibliography.
\end{abstract}

Keywords: slavery, proposal, bibliography, literature 
La grande douleur du monde: notes pour l'étude de l'esclavage, tirées de l'histoire et de la littérature cubaines

\section{Résumé}

Le travail présenté: La grande douleur du monde: notes pour l'étude de l'esclavage, de l'histoire et de la littérature cubaines, est une proposition didactique qui vise à proposer des œuvres littéraires qui abordent le sujet de l'esclavage sous différents angles. Le thème proposé répond à un problème social de grande importance: l'héritage des cultures africaines à la consolidation de la nation cubaine et donc à l'identité et à la culture. La proposition est faite dans une perspective interdisciplinaire entre littérature et histoire. Pour l'étude, des ouvrages de grande importance qui établissent des normes dans le traitement du sujet dans la littérature mondiale ont été analysés et proposés sous forme de bibliographie. Le travail consiste en une introduction où le contexte de l'étude est proposé en tenant compte des auteurs les plus significatifs, un développement où les travaux proposés sont analysés et des références bibliographiques qui abordent le sujet sont exposées, des conclusions et une bibliographie.

Mots-clés: esclavage, proposition, bibliographie, littérature,
Wstyd dla swiata: notatki do badania niewolnictwa $\mathrm{z}$ perspektywy kubanskiej historii literatury

\section{Streszczenie}

Przedstawione dzieło: Wstuyd dla świata: notatki do badania niewolnictwa, $\mathrm{z}$ kubańskiej historii liiteratury, jest dydaktyczną propozycją, która ma na celu zaproponowanie dzieł literackich, które odnoszą się do kwestii niewolnictwa $\mathrm{z}$ różnych perspektyw. Proponowany temat jest odpowiedzia na problem społeczny o wielkim znaczeniu: dziedzictwo kultur afrykańskich dla konsolidacji narodu kubańskiego, a tym samym tożsamości i kultury. Wniosek składa się z interdyscyplinarnego punktu widzenia między literatura a historia. W badaniu przeanalizowano prace o dużym znaczeniu, które wyznaczają wytyczne w literaturze uniwersalnej i są proponowane jako bibliografia. Praca składa się $\mathrm{z}$ wprowadzenia, gdzie tło badania uwzględnienia najbardziej znaczących autorów, rozwój, w którym proponowane prace są analizowane i odniesienia bibliograficzne, które odnoszą się do tematu. $\mathrm{Na}$ koncu pracy znajduja sie wnioski i bibliografia.

Slowa kluczowe: niewolnictwo, propozycja, bibliografia, literatura 


\section{Antecedentes}

La historia de la esclavitud de hombres y mujeres provenientes de África, no comienza con su llegada a América; sus antecedentes se enmarcan en la Península ibérica.

En el ámbito peninsular, la esclavitud era practicada antes del descubrimiento, al amparo de las posibilidades que ofrecía la servidumbre dentro de la sociedad feudal. Si bien la mayor parte de los esclavos que llegaron a América fueron introducidos directamente desde África, también los hubo que hicieron escala en España y otros que se quedaron definitivamente en la península (García, 2013, p. 23).

En Cuba, la esclavitud fue resultado del desarrollo económico que había alcanzado España. Según Jesús Guanche (20II), "Los primeros africanos vienen con Cristóbal Colón, en sus diferentes viajes, pero estos son solo sirvientes domésticos" (p. Io). De ahí que, asociar el origen de la esclavitud al Padre Bartolomé de las Casas, constituye un error corregido actualmente en varias fuentes bibliografías.

Diferentes autores han abordado el tema de la esclavitud y sus trabajos se sustentan en búsquedas bibliográficas, estudios de campo, entrevistas, entre otras técnicas. Uno de los aportes más importantes descansa en la definición etimológica del flagelo. Así, para Oruno D. Lara, la esclavitud consistió esencialmente en una relación de dominación; se basó en la autoridad del amo, que se imponía por la fuerza o la amenaza. Desde su óptica:

El sistema esclavista fue instaurado y mantenido por la violencia. Azotar a los esclavos no representaba solo un castigo, era también una manera de dominarlos, de amedrentarlos y recordarles su servidumbre. Los esclavos estaban condenados a vivir dispersos, sin más alternativa que la sumisión abyecta, la fuga o la rebelión (Lara, 2004, párr. 3). 
El esclavo negro apareció como mano de obra para el trabajo en el nuevo continente, fundamentalmente para pagar deudas contraídas en la búsqueda de oro, después del despoblamiento aborigen. De esta forma, los africanos llegaron a América arrancados de su tierra y cultura, encadenados y en condiciones inhumanas.

En la obra Cuatro Siglos de Esclavitud Trasatlántica, publicada en 20I7, Kenneth Morgan realiza un estudio detallado de la trata esclavista. Este autor comienza su análisis a partir de la revisión de otros trabajos que se realizaron durante el siglo XX, pero con datos muy diferentes; por lo que sus propuestas estadísticas parten de la Transatlantic Slave Trade Database, que ofrece información detallada para un análisis más exhaustivo del fenómeno. El autor plantea que se realizaron 33360 viajes, que embarcaron Io I48 288 esclavos en África y de 33048 viajes desembarcaron 8752924 esclavos, principalmente en las Américas, entre principios del siglo XVI y mediados del siglo XIX.

El tráfico de esclavos estuvo determinado por las principales potencias comerciales de Europa Occidental, que establecieron franca competencia entre ellas por el tráfico ultramarino en los inicios de la era moderna y en el denominado proceso de conquista y colonización. En las colonias establecidas en América las materias primas que mayor demanda alcanzaron -y por tanto las más exportables- fueron principalmente el azúcar, el tabaco, el algodón y el café. El cultivo y el comercio de estos productos requirieron de gran cantidad de mano de obra para realizar las tareas de cosecha y posterior traslado a los barcos para su comercio. A partir de ello las potencias europeas fueron responsables del $55.2 \%$ de los esclavos que cruzaron el Atlántico entre I50I y I866. Los principales puertos ibéricos del tráfico fueron Lisboa, Bahía, Recife y Río de Janeiro, según la información ofrecida por Kenneth Morgan. "El volumen del comercio entre Portugal y Brasil fue especialmente grande en el siglo XIX: cuatro de cada diez africanos transportados a las Américas por este pabellón nacional fueron enviados entre I80I y I866" (Morgan, 20I7, p. 33). 
Plantea Morgan, que durante el siglo XVI Inglaterra, Holanda y Francia, desempeñaron un papel menos significativo en los flujos de la trata de esclavos, por no tener del otro lado del atlántico colonias importantes, pero esto no ocurrió de igual forma en el siglo XVII cuando estas potencias establecieron colonias y aumentaron el tráfico de esclavos. Inglaterra colonizó gran parte de la costa oriental de Norteamérica en el siglo XVIII y se hizo con varias islas caribeñas, mientras que Francia y Holanda fundaron colonias en las Indias Occidentales y los holandeses lograron establecerse en pequeños territorios (Demerara, Esequibo, Berbice y sobre todo Surinam).

Inglaterra fue la potencia europea que transportó mayor número de esclavos, por ser la que mayor territorio abarcó en América. En 1775 ocupaba más del doble de millas cuadradas que los imperios atlánticos de Holanda y Francia juntos. El comercio de esclavos británico alcanzó su máximo apogeo en el siglo XVIII. "Entre I660 y I807, año en que Inglaterra abolió este tráfico, los buques que zarpaban de los puertos ingleses hacia Norteamérica y el Caribe embarcaron a más de tres millones de esclavos" (Morgan, 20I7, p. 34).

Otro aspecto histórico sobre el tema de la esclavitud y los aportes culturales que los africanos realizaron a América, está basado en el lugar de procedencia de esa mano de obra, destinada al trabajo esclavo. Según los estudios etnodemográficos de Jesús Guanche:

La zona de procedencia de los esclavos llegados a Cuba corresponde fundamentalmente a la costa occidental de África, desde Cabo Blanco hasta el sur de Angola. En mayor o menor proporción aparecen de zonas del interior del continente y como es el caso excepcional, de la región oriental bañada por el Océano Índico. La inmensa mayoría de estos pueblos pertenecen al grupo lingüístico Níger-Congo, de la familia nigero-cordófona (Guanche, 2009, p. 37). 
Otra de las claves sobre el tema la ofrece don Fernando Ortiz, Del fenómeno social de la transculturación y de su importancia para Cuba, cuando expresa:

Los negros trajeron con sus cuerpos sus espíritus, (¡mal negocio para los hacendados!), pero no sus instituciones, ni su instrumentario. Vinieron multitud de negros con multitud de procedencias, razas, lenguajes, culturas, clases, sexos y edades, confundidos en los barcos y barracones de la trata y socialmente igualados en un mismo régimen de esclavitud. Llegaron arrancados, heridos y trozados como las cañas en el ingenio y como éstas fueron molidos y estrujados para sacarles su jugo de trabajo. No hubo otro elemento humano en más profunda y continua transmigración de ambiente, de cultura, de clases y de conciencias. Pasaron de una cultura a otra más potente, como los indios; pero estos sufrieron en su tierra nativa, creyendo que al morir pasaban al lado invisible de su propio mundo cubano; y los negros, con suerte más cruel, cruzaron el mar en agonía y pensando que aún después de muertos tenían que repasarlo para revivir allá en África con sus padres perdidos. Fueron los negros arrancados de otro continente como los blancos, es verdad; pero ellos vinieron sin voluntad ni ambición, forzados a dejar sus libres placideces tribales para aquí desesperarse en la esclavitud (Ortiz, 1963, p. 99).

Muchos estudios han dedicado páginas valiosas a describir e historiar estas travesías. Una de las obras monumentales que aborda este proceso, es El barco de esclavos, una historia humana, de Markus Rediker publicada en 20I4. En ella se aborda el tema de la travesía ilegal y clandestina de los que vinieron desde el continente africano para sustentar económicamente a América. Este autor revisó archivos de Europa y América, de manera que verificó cartas y diarios de traficantes y tratantes. La obra está llena de ejemplos desgarradores ocurridos, durante las muchas travesías hacia América, donde lanzar uno o varios hombres al mar era de lo más común que podía pasar en el trayecto. 
Otros morían por enfermedades o por suicidios. De ahí que este autor afirme, que más de un millón de personas murió en la trata.

En El Barco de Esclavos, una historia humana el autor abordó tres dramas sufridos por los africanos antes de llegar a su destino. El primer drama consistía en las relaciones entre el capitán del barco de esclavos y su tripulación, hombres que, en el lenguaje de la época, no debían tener "ni dedos, ni narices delicadas" dado que el de ellos era un oficio sucio en todos los sentidos posibles; el segundo estaba relacionado, a partir de los vínculos establecidos entre los marineros y los esclavos. Debido a ello: "Las relaciones entre los marineros y los esclavos - basada sobre la alimentación forzada en forma inhumana, azotes, violencias ocasionales de todo tipo y la violación de cautivas". (Rediker, 20I4, p. 7).

El tercero:

Tenía que ver con la cooperación entre los esclavizados, dado que eran personas de clases, etnias y géneros diferentes amontonados en la horrorosa cubierta interior del barco de esclavos. ¿Cómo lograban comunicarse esta "multitud de negros de todo tipo encadenados juntos"? Encontraron maneras de intercambiar información valiosa sobre todos los aspectos de su situación, el lugar al que se dirigían y su suerte futura. En medio de la brutal presión, el terror y la muerte prematura, se las ingeniaron para dar una respuesta creativa y afirmadora a la vida: idearon nuevas lenguas, nuevas prácticas culturales, nuevos vínculos y comunidad naciente de quienes viajaban juntos. Se llamaban unos a otros "carabela", lo que equivalía a hermano y hermana... (Rediker, 20I4, p. 7).

La obra de Markus Rediker -reeditada por la Casa de Altos Estudios Don Fernando Ortíz-, fue el resultado de un profundísimo estudio sobre la trata esclavista en disímiles aspectos, que van desde las 
relaciones interpersonales entre todos los factores que participaron en el inescrupuloso fenómeno social de la trata esclavista, que sustentó la economía en América y cambió los destinos del mundo entre los siglos XV y XIX.

Sin embargo, los tres continentes que formaron parte de este proceso social, no llevaron la misma parte en la historia ni en los destinos económicos. La esclavitud significó para Europa el desarrollo de la Revolución Industrial, sostuvo el orden colonial e hizo fuerte el capitalismo europeo, a partir de las ganancias obtenidas en la minería, la siembra de algodón, los cafetales y las plantaciones, entre otros renglones económicos. España a través de diversos mecanismos colonizadores, siempre llevó la mejor parte. Para América, la entrada de esclavos significó el respiro y el aliento económico borrado por sus poblaciones autóctonas, tras el encuentro tortuoso entre dos culturas bien diferentes donde la parte conquistadora se impuso a la fuerza.

Habría que estudiar profundamente la obra Las venas abiertas de América Latina (2004), de Eduardo Galeano, para enjuiciar lo que significó el proceso de colonización para América, la masacre a poblaciones autóctonas y el robo despiadado a sus recursos naturales, convirtiendo a América, con el paso inexorable del tiempo, en abastecedora de productos manufacturados.

La división internacional del trabajo consiste en que unos países se especialicen en ganar y otros en perder. Nuestra comarca del mundo, que hoy llamamos América Latina, fue precoz: se especializó en perder desde los remotos tiempos en que los europeos del Renacimiento, se abalanzaron a través del mar y le hundieron los dientes en la garganta (Galeano, 2004, p. I7).

Otro texto que muestra con exactitud las relaciones del proceso de la esclavitud con el posterior desarrollo de la clase obrera es la obra De la esclavitud al trabajo asalariado, publicado en el 2007 por Ediciones Akal, de la autoría de Yann Moulier Boutang, dividido en cuatro temáticas 
fundamentales, basadas en el lugar histórico que le ha correspondido a los procesos migratorios en la conformación de las naciones, a través de todos los tiempos; las especificidades sociales de la mano de obra extranjera, a partir de lo cual ofrece un análisis de la antigua esclavitud, que aporta aspectos históricos esclarecedores a nuevos procesos que convierten a la fuerza de trabajo en dependiente; se realiza un estudio del modelo colonial inglés sobre la base del trabajo asalariado. De manera general, la obra realiza un análisis detallado de la esclavitud, en toda la amplitud del término, a partir de los diferentes estadios por los que ha transitado la humanidad, deteniéndose en la forma en que cada uno de ellos da lugar a otro. Según las reflexiones de este autor, en la sociedad actual el hombre está participando en un nuevo proceso de esclavitud, esta vez condicionado por las relaciones establecidas entre la fuerza de trabajo y las relaciones de producción. Se detiene también en la constitución de la clase obrera, afirmando: "Esta última, se construyó sobre una ruptura radical con los pobres, con los campesinos y con aquello que permitió la disciplinarización y la fijación de los pobres: el paso por las colonias, la esclavitud, la servidumbre y la organización del trabajo en brigadas"(Avilés, 2020: Documento digital. Resumen) (2020,20 de junio). Otro de los aportes fundamentales de la obra lo constituye el análisis realizado al papel desempeñado por las migraciones de todo tipo en la constitución de la mano de obra y por tanto de la economía de las naciones. La propuesta de Yann Moulier Boutang aporta datos esclarecedores para comprender en toda su dimensión lo que significó el proceso de la esclavitud para los tres continentes (África, Europa y América) que formaron parte de esta página de la historia de la humanidad.

De este modo los esclavos se convirtieron en la base económica de América y fue su trabajo, su esfuerzo y su sangre la simiente de la cual germinó la nueva América. Sin embargo, el continente africano aún no se ha recuperado del despoblamiento a que fue sometido, debido a que los hijos que le llevaron eran en su mayoría hombres, jóvenes y fuertes que pudieran sustentar el lucrativo negocio. Por supuesto que también 
trajeron gran cantidad de mujeres, las necesarias como para perpetuar el inhumano proceso de la esclavitud.

El sistema social cubano, sustentado por el trabajo esclavo, a través de sangrientas represiones, ubicó al blanco y al negro en distintos niveles. Al blanco, le perteneció la posición de amo, señor y dominador; al negro africano, le correspondió la sumisión, el esfuerzo y la abnegación.

En la obra La economía en la novela cubana del siglo XIX, el autor compara las posiciones sociales en que fueron colocados blancos y negros a partir del sistema económico basado en el trabajo esclavo:

El africano libertó al blanco de casi toda actividad productiva y lo condenó al ocio, la inmoralidad y el vicio. El blanco condenó al esclavo a un trabajo vejaminoso y de exterminio. Deshumanizados, ambos se enfrentaron con una violencia desgarradora, implacable: la lucha de clases, fue lucha de razas (Sosa, I978, p. 6).

Muchas obras de la literatura universal y cubana describen el proceso de la captura trueque o negocio -como se le quiera llamar- según las diferentes formas que tuvo la trata atlántica. Una de las más sencillas, tristes y claras al respecto lo constituye el testimonio Reyita, sencillamente (2OII), de Daysi Rubiera Castillo:

En un atardecer cuando la familia estaba en su casa después de haber terminado el trabajo en el campo y los niños jugaban, de pronto sintieron explosiones y gritos. Era que un grupo de hombres blancos con armas de fuego, atacaba la aldea, quemaba las casas y cogía a hombres y mujeres, mataba a niños y ancianos. Aquello fue una terrible carnicería. Mi bisabuela vio desaparecer a su hijo y a su marido; a las hembras trató de defenderlas como pudo, pero la golpearon y le llevaron a tres mayores: Tatica, Casilda y Nestora. Mi abuela nunca olvidaría los gritos de su madre, ni nunca pudo explicar por qué no 
cargaron también con ella, pues no era tan vieja; tampoco supo si sobrevivió a todo aquello.

El barco en que las sacaron de África estaba atestado de hombres, mujeres y hasta niños, esos eran los menos... Ella decía que fueron algunos que no pudieron arrancárselos a sus madres. Como venía tan lleno se presentaron dificultades [...] comenzaron a tirar hombres al agua, fundamentalmente los más viejos, los más endebles (Rubiera, 20II, p. I8).

En esta novela-testimonio, la autora no solo aborda el tema de la pasada esclavitud, sino los problemas y desprecios sociales que les causó a Reyita (personaje protagónico) ser negra. Hasta su madre la despreciaba y apartaba. Al final de su historia descubre que su esposo, con quien ha pasado la vida, no estuvo legalmente casado con ella, a causa de su condición racial.

En el año 1966, una obra etnográfica y testimonial marcó los destinos de la literatura cubana: Biografía de un cimarrón, de Miguel Barnet. La obra parte de una entrevista realizada por el autor a Esteban Montejo, anciano que había sido esclavo y cimarrón. Gracias a las técnicas de entrevistas no estructuradas utilizadas por Barnet, nos cuenta, en primera persona, qué fue la vida en los barracones, cómo estaban divididos por dentro, ocasionando las más diversas vicisitudes y condiciones inhóspitas que pueda pasar un ser humano.

Todos los esclavos vivían en barracones. Ya esas viviendas no existen, así que nadie las puede ver. Pero yo las vide y no pensé nunca bien de ellas. Los amos sí decían que los barracones eran tacitas de oro. A los esclavos no les gustaba vivir en esas condiciones porque la cerradera les asfixiaba. Los barracones eran grandes, aunque había algunos ingenios que los tenían más chiquitos; eso era de acuerdo a la cantidad de esclavos de una dotación. En Flor de Sagua vivían como doscientos esclavos de todos los colores. Ese era en forma de hileras: dos hileras que se 
miraban frente a frente, con un portón en el medio de una de ellas y un cerrojo grueso que trancaba a los esclavos por la noche. [...] Un hoyo en la pared del cuarto o una ventanita con barrotes eran suficientes. De ahí que abundaran las pulgas y las niguas que enfermaban a la dotación de infecciones y maleficios (Barnet, 20I6, p. 3I).

En un primer momento de la obra, Montejo aborda aspectos de la vida social cubana generados por el sistema de plantación esclavista; luego, su estancia en el monte, una vez que decide huir y dejar de ser esclavo. Hay un hecho significativo, cuando el protagonista descubre que es libre:

Cuando salí del monte me puse a caminar y encontré a una vieja con dos niños de brazos. La llamé de lejos y cuando ella se acercó le pregunté: Dígame, ¿es verdad que ya no somos esclavos? Ella me contestó: No hijo, ya somos libres (Barnet, 20I6, p. 60).

Seguidamente Esteban Montejo cuenta como continuó manifestándose el desprecio y la discriminación racial, aun cuando ya había pasado oficialmente la esclavitud. Asegura que muchos antiguos dueños de esclavos seguían tratando a los libertos como si todavía fueran esclavos y, muchos obedecían a los "señores".

Biografía de un cimarrón, además de ser el testimonio de un hombre que fue esclavo, cimarrón y vivió hasta la época de la Revolución, es una crónica social y cultural de su tiempo, donde se describen las costumbres, las tradiciones, los juegos, los bailes, la música, todo ello contado a partir de la visión del que está en una posición de observador y buscándole respuestas a un fenómeno que no entiende cómo fue qué pasó. De esta manera, sin tener consciencia de que los planteamientos responden al más alto linaje filosófico, Esteban Montejo afirma:

No sé cómo permitieron la esclavitud (los dioses). La verdad es que yo me pongo a pensar y no doy pie con bola. Para mí que 
todo empezó cuando el pañuelo punzó. El día que cruzaron la muralla. La muralla era vieja en Âfrica en toda la orilla. Era una muralla hecha de yaguas y bichos brujos que picaban como diablo. Espantaron por muchos años a los blancos que intentaron meterse en África. Pero el punzó los hundió a todos. Y los reyes y todos los demás se entregaron facilito. Cuando los reyes veían que los blancos, yo creo que los portugueses fueron los primeros, sacaban los pañuelos punzó como saludando, les decían a los negros: "Anda, ve a buscar pañuelos punzó, corrían como ovejitas para los barcos y ahí mismo los cogían [...] Y después no pudieron volver a su tierra. Esa es la razón de la esclavitud en Cuba (Barnet, 20I6, p. 26).

Como ya se conoce, una vez que llegaban a América, a los africanos les esperaban cruentas condiciones y horribles maltratos, que iban desde la discriminación social y racial, hasta las más despiadadas agresiones físicas.

Biografía de un cimarrón, tiene grandes valores históricos y patrimoniales que han generado toda una gama de estudios y teorías a partir de sus 64 ediciones en muchísimos países del mundo. La narración de Esteban Montejo pasa el lente del más acucioso investigador de la cultura cubana. En las páginas de este libro el devenir de su vida, es motivo para caracterizar de manera brillante, los períodos históricos que vivió, desde las varias estructuras económicas que expresaron los contextos sociales. Es así que el autor describe fiestas populares de blancos, de negros, formas de vestir, de curarse, de alimentarse, en fin, todo un tratado de cultura popular tradicional, entre sus muchos valores.

Miguel Barnet, antes de organizar las entrevistas que le realizara a Esteban Montejo, ya era un joven investigador vinculado a importantes etnógrafos cubanos como Argeliers León, María Teresa Linares, Juan Pérez de la Riva, Manuel Moreno Fraginals, entre otros. Trabajar con este equipo -además de las visitas que le realizaba a Don Fernando Ortiz, unido a su interés y talento- lo llevó a descubrir en Montejo, a un 
informante que le aportaría otra mirada a la historia de la nación cubana, la mirada de adentro, del sujeto marginado que, en su ciento y tantos años, no tuvo nada que ganar ni perder. Sin embargo, las relaciones del investigador con el informante no fueron frías, ni distantes. Los vínculos establecidos constituyen un tratado de investigación antropológica y el mejor de los libros de metodología de la investigación social que pueda consultar un joven investigador. El ensayo, Para llegar a Esteban Montejo: los caminos del cimarrón, que aparece recogido en el volumen de ensayos La fuente viva, publicado en el año 20II por el propio autor, expone la armónica comunicación producida entre ambos. Así lo describió Barnet:

Biografía de un cimarrón salió en 1966 y, de entonces acá, Esteban Montejo es algo que está en lo más profundo de mi memoria y mi corazón y diría más: es una presencia que me acompaña. Cuando se me ha olvidado un 26 de diciembre, cuando no le hecho un homenaje por la mañana con un pensamiento hacia él, me lo ha recordado el hecho de que ese día también coincide con el cumpleaños de Alejo Carpentier. Entonces me viene de nuevo Esteban Montejo y recuerdo mis diálogos con él, y aquel gran rapport, aquella comunicación que se produjo entre nosotros y parece que nunca va a acabar (Barnet, 20II, p. 22).

La Cabaña del Tío Tom, de la autora Harriet Beecher Stowe, a pesar de no reflejar el drama de la esclavitud en Cuba y sí en el norte de América, nos parece oportuno reseñarla por la precisión con que aborda el tema, desde la psicología de los personajes, ubicados socialmente en diferentes peldaños. En el momento de su publicación, la magnitud e importancia de la novela fue tal que, en un encuentro con ella, el presidente Lincoln le preguntó: ¿Esa es la pequeña mujer que desató la guerra civil? Publicada, cuando la esclavitud no había sido abolida, fue motivo de escándalo en la sociedad y desató una cantidad de cartas preguntando si Tom y los demás personajes existían, a lo que Beecher Stowe respondía afirmativamente. 
La obra constituye una protesta hacia la esclavitud y cuenta las vicisitudes de estos hombres. Principalmente, se detiene en las quebrantadas relaciones familiares de los esclavos, el amor y penas de las madres al separarse de sus hijos pequeños. Esto tenía un objetivo: la primera tirada de la novela salió en revistas destinadas a mujeres. De esta forma hacía conciencia respecto al fenómeno. Narra la autora en voz de un personaje:

Conocí a una muchacha muy guapa una vez en Nueva Orleans que se echó a perder del todo por un trato así. El tipo que la vendía no quería a su hijo, y ella era altiva cuando se enfadaba. Le digo que estranguló a su hijo con sus manos y siguió hablando de manera terrible. Me hiela la sangre recordarlo; y cuando se llevaron al hijo y a ella la encerraron, se volvió loca de atar y al cabo de una semana estaba muerta. Un desperdicio, señor, de mil dólares, sólo por no saber hacer negocios, esa es la verdad (Beecher, I973, p. 32).

En La Cabaña del tío Tom, la trama esencial de la obra se basa en el trato deshumanizado que reciben los esclavos; toma como eje central la vida de Tom, un esclavo doméstico, fiel al extremo de abrazar el cristianismo como religión y aceptar su existencia porque viene de un mandato divino. Tom es vendido constantemente y rebajado a la más inconcebible condición. Por supuesto, la obra está matizada con hechos asociados a desgracias que, en su conjunto, dan la idea de una vida desgarradora en todos los sentidos. Al final, la novela, como obra romántica destinada al público femenino —en su primera tirada-, incorpora a un héroe blanco que va en busca del esclavo Tom para otorgarle su libertad como recompensa a su lealtad, pero llega tarde.

En Cuba, la esclavitud generó toda una inquietud literaria. El avance económico alcanzado a mediados del siglo XIX, como resultado de la producción azucarera, provocó que medio millón de esclavos fueran traídos a la Isla destinados a trabajar en las plantaciones cañeras y de café y en las vegas de tabaco. 
Las principales novelas de la época no escaparon al tema, iniciándose así una nueva tendencia en el campo de la narrativa, admitida como literatura antiesclasvista. Francisco, de Anselmo Suárez y Romero (I838) y Petrone y Rosalía de Félix Tanco, son muestras de la concepción inaugurada. La poesía tampoco escapó a ese flagelo. Así lo expresa José María Heredia en estos versos: las bellezas del físico mundo, los horrores del mundo moral.

El mérito fundamental de estas obras, independientemente de la trascendencia literaria, se halla en que fueron escritas en pleno sustento de la esclavitud como base económica de la sociedad cubana, por tanto, constituyen referentes y puntos de partida obligatorios para estudiar la novela antiesclavista en Cuba.

En estos relatos es común el recuento de los infortunios de los personajes. Los protagonistas son esclavos domésticos que, debido a las vejaciones realizadas por sus amos, son enviados al campo como castigo. En Petrone y Rosalía salen a la luz las mezquindades de alma de las familias de esclavistas cubanos, donde muchos de ellos, como se ha podido comprobar después, mantienen relaciones adúlteras con las esclavas. Petrone es obligada por su amo, don Antonio Malpica, a tener relaciones sexuales con él. De esa unión nace Rosalía, en la plantación cañera porque la señora mandó que la sacaran de la casa, solo por el hecho de estar embarazada sin saber la relación forzada de esta con su esposo. Rosalía corre el mismo infortunio que la madre: tiene relaciones con el hijo del amo, al parecer su medio hermano. Hasta que la verdad se conoce: doña Concepción había tenido un romance con uno de los que frecuentaba la casa. De ahí nació su hijo, no del amo Antonio Malpica. De esta forma, el autor salva a sus personajes de una relación incestuosa, como ocurriría en la novela de Cirilo Villaverde.

Francisco de Anselmo Suárez y Romero es una obra que, aunque no se atreve a acusar a la esclavitud como institución capaz de engendrar males sociales, si le proporciona desniveles a las columnas que la sustentan; a partir de la crítica que realiza en la propia vida desgraciada 
de Francisco, el personaje que ha creado. A esta novela, de forma irónica, Domingo del Monte dio el título de El ingenio o las delicias del campo. En ella, el autor muestra cómo estaba organizado el trabajo en los ingenios, cómo era la vida de los esclavos domésticos, habla de sus fiestas, de su religión, toda una descripción del medio en que se desarrollaba la esclavitud a partir de los infortunios sufridos por Francisco y Dorotea. Esta última convertida en la obsesión del señorito Ricardo, presentado por el escritor como un mal educado, consentido y carente de los más elementales principios del ser humano, quien descarga todo el odio de su frustración en Francisco. En la novela aparecen otros personajes descritos en toda su paradójica situación como el mayoral, el médico y el ama. Sin embargo, en su tiempo, a Anselmo Suárez y Romero se le criticó la situación sumisa de Francisco, que soportaba todos los maltratos y vejaciones sin revelarse ante su situación. Hecho que el novelista justificaba a partir de su propia condición cristiana. A decir de Denia García Ronda:

Aunque en Francisco se describe la explotación a los esclavos y los abusos cometidos contra ellos, lo que se está propugnando es en última instancia, la necesidad de un mejor trato, y la consideración de los esclavos como seres humanos capaces de virtudes y sentimientos y no piezas o sacos de carbón como los llamaba la retórica esclavista. Cosa, que para su momento ya era considerada subversiva para las autoridades y los esclavistas más recalcitrantes, por lo que no se publicó en Cuba hasta la década de los 80 del siglo XIX (García, 2015, p. I26).

El tema de la esclavitud generó polémicas sociales expresadas no solo en la literatura, sino en las encontradas posiciones a favor y en contra que tomaban los implicados en el asunto. En las novelas anteriormente mencionadas, el esclavo doméstico jugó un papel determinante. Presentado como un adorno, un objeto para ser exhibido y que solo en muy determinados momentos, tuvo alguna forma de rebeldía ante la realidad que le tocó. 
Anselmo Suárez y Romero, y Félix Tanco asistían a las tertulias realizadas en ciudad de La Habana y Matanzas, por el rico hacendado Domingo del Monte, figura controversial en la historia de la literatura cubana. José Martí lo llamó "el más real y útil de los cubanos de su tiempo" no porque fuera un dechado de virtudes, pues fue hijo de su tiempo y representante de la clase social a la que pertenecía. Sin embargo, sí le correspondió el mérito de haber condenado la esclavitud, a través de las tertulias y de su labor de mentor y crítico de importantes escritores de su tiempo, convirtiéndose en el centro de muchos proyectos literarios.

En las tertulias delmontinas se criticó y cuestionó la esclavitud desde diversos puntos de vista y opciones, pero siempre con una mirada antiesclavista. Un hecho constituyó el punto final e inspiración de estas obras: fue la lectura del soneto Treinta años del poeta esclavo Juan Francisco Manzano. El poema reza:

Cuando miro el espacio que he corrido desde la cuna hasta el presente día, tiemblo, y saludo a la fortuna mía, más de terror que de atención movido.

Sorpréndeme la lucha que he podido sostener contra suerte tan impía, si tal llamarse puede la porfía de mi infelice ser, al mal nacido.

Treinta años ha que conocí la tierra; treinta años ha que en gemidor estado triste infortunio por doquier me asalta;

Mas nada es para mí la cruda guerra que en vano suspirar he soportado, si la calculo, ¡oh Dios!, con lo que falta (Manzano,20I5, p. I9). 
A pesar de que no existe documento que testimonie el hecho, los asistentes a la tertulia realizaron una colecta para comprar la libertad de Juan Francisco Manzano a su última ama, la señora María de Luz de Zayas. Afirma también Alex Castro, en los comentarios que realiza a la Autobiografía de Francisco Manzano:

Manzano y Del Monte fueron amigos; pero Manzano jamás se atrevió a sentarse en su presencia y permanecía siempre de pie, por su parte, Del Monte no lo invitó a su casamiento, ni le comunicó sobre ello. La relación entre los dos -¿amistad?solamente puede ser comprendida dentro del sistema del cual formaban parte: una sociedad en que la ley otorgaba los mismos derechos a personas negras libres y a personas blancas, pero al mismo tiempo exigía que las negras fuesen subordinadas a las blancas (Castro, 20I5, p. 78).

La lectura de la Autobiografía de Juan Francisco Manzano (20I5), en las tertulias de Domingo del Monte, generó las dos novelas mencionadas, de los autores Félix Tanco y Anselmo Suárez y Romero:

¿Cómo influiría en estos contertulios la lectura de los recuerdos autobiográficos del esclavo? Tanto Suárez y Romero como otros reaccionaban de manera sentimental, lloraban mientras leían las calamidades sufridas por el esclavo. Algo más profundo debía quedar impreso en su sensibilidad, que de alguna manera iban a transmitir a sus obras (Bueno, I988, p.3).

Pasado el tiempo, su lectura sigue acongojando y entristeciendo la sensibilidad humana. Ese Manzano que escribiría en I835 a Domingo del Monte:

A un cuadro de tantas calamidades, no parece si no, un abultado protocolo de embusterías y más, desde tan tierna edad los azotes me hacían conocer mi humilde condición [...] acuérdese su 
merced, cuando lea, que yo soy esclavo y que el esclavo es un ser muerto ante su señor (Martínez, 2009, p. I5).

A pesar de que trató de no ser excesivo en su narración, cuenta Manzano, que de niño fue castigado por acariciar unas hojas de geranio, placer prohibido por un ama caprichosa, quien lo consideraba indigno del halago de la naturaleza. Entre otras anécdotas describe como fue separado de los suyos, vio azotar a su mamá; llorar a sus hermanos; convivió con las ratas; fue condenado por cambiar una moneda suya por otra que brillaba más, pero del mismo valor. Fue humillado y despreciado hasta por los que él creía que lo apreciaban un poco. Y todavía cuando fueron a comprar su libertad el ama lo acusó de ingrato.

Libre, tampoco pudo Manzano acariciar su libertad: fue envuelto en el torbellino oscuro que la historia recoge como los sucesos del año I844 o "Año del cuero" a partir de sublevaciones simultáneas de esclavos en diferentes ingenios. Aun la historia no ha podido precisar, si realmente hubo conspiración alentada por los ricos hacendados criollos y los abolicionistas ingleses o se trató de un pretexto utilizado por España para quebrar todo intento de Revolución como ocurrió en Haití. En este proceso Manzano fue juzgado, jamás acusó a los blancos con los que se rodeaba, a los cuales les debía su primera libertad. Al contrario:

Más tarde conocería Domingo que, entre los "hombres de color", uno levantó su voz para defenderlo, enfrentándose con firmeza a los calumniadores: Juan Francisco Manzano, poeta y fabricante de dulces. Reo también en el arbitrario proceso, el esclavo no olvidó la contribución de los jóvenes ilustrados en la empresa de conseguir su libertad y supo comportarse estoicamente, sin ceder a presiones y amenazas, prefiriendo soportar humillaciones y maltratos antes que ofrecer testimonios falsos. Llevado, por orden del fiscal, a un careo con Plácido, negó las imputaciones comprometedoras que este hiciera a Del Monte, e insistió en el prestigio del mentor, propugnando su inocencia (Martínez, 2009, p. 437). 
Después de los sucesos que dieron lugar a la Conspiración de la Escalera, Manzano enmudeció para siempre y jamás se supo nada de su obra posterior. A causa de la conspiración perdió la vida el también poeta Gabriel de la Concepción Valdés (Plácido), en torno a quien la historiografía cubana se debate entre el mito y la realidad.

Placido llegó a la vida marcado por la desgracia y abandono, pues fue dejado en una casa cuna, por lo que lleva el apellido Valdés. Fue hijo de una bailarina española y un peluquero mulato, que a los pocos meses de nacido lo sacó de la casa cuna, pero Plácido nunca se quitó el apellido de Valdés. Al parecer tuvo relación directa con la intelectualidad de su tiempo, acusada también de impulsar el movimiento conspirativo, pero que en la persona de Domingo del Monte, negó todo tipo de vínculos con el poeta, condenado al paredón. La vida y la obra de Plácido fue estudiada con profundidad por la investigadora cubana, Daisy Rubiera Cue, quien como resultado de sus estudios publicó la obra Plácido el poeta conspirador, donde analiza los aspectos históricos que vincularon al poeta a la conspiración y cómo su situación social fue abordada en su poesía: Porque todo viviente, por instinto, huye de la opresión y de la muerte. (Rubiera, 2007, p. I67)

La tercera novela antiesclavista de este período es $S a b$, escrita en España por Gertrudis Gómez de Avellaneda. Esta obra describe, con mayor agudeza que en las dos obras anteriores, el problema de la esclavitud. La trama esencial está basada en el sentimiento amoroso del esclavo Sab, hacia Carlota, hija de su amo.

Sin embargo, Sab no es un esclavo como los demás: ha recibido educación junto con Carlota, está representado como hijo de una princesa africana. Con este referente la autora también se aleja de la gran masa de esclavos, sostén de la sociedad colonial. En la novela Sab, aparece una total denuncia a la esclavitud a partir de los postulados del esclavo protagónico, pero siempre desde la retórica, desde el discurso, nunca desde los hechos. Como personaje romántico al fin, Sab es capaz de renunciar a su propia libertad por amor. Además del tema de la 
esclavitud, la Avellaneda, hace una crítica contundente para su tiempo al papel de la mujer en la sociedad cubana, comparándola con la vida del esclavo. “¡Oh! ¡Las mujeres! ¡Pobres y ciegas víctimas! Como los esclavos ellas arrastran pacientemente su cadena y bajan la cabeza bajo el yugo de las leyes humanas" (Gómez, 2000, p. I2).

Según Denia García Ronda: "Es la más progresista de las que se escriben en la primera mitad del siglo XIX acerca del tema; pues va más allá de la denuncia de la esclavitud para llegar a propugnar la igualdad de las razas" (García, 20I5, p. I27).

Ninguna de las novelas anteriores pudo conocerse en Cuba en el momento en que se escribieron, circularon en reducidos espacios. En nuestra literatura, a pesar de las limitaciones señaladas, $S a b$ representó un referente literario que expresó, desde diversas posiciones críticas, el problema de la esclavitud.

No fue hasta el año I862 cuando Cirilo Villaverde escribió una obra cumbre de la literatura social cubana: Cecilia Valdés o La loma del ángel, novela que ha merecido el epíteto de retrato de la época, por la maestría con que el autor describe la sociedad cubana y trata el tema de la esclavitud, convirtiéndose en una obra paradigmática del siglo pasado. En sus páginas se describen los maltratos que recibían los esclavos. En una de sus escenas, cuenta como Leonardo Gamboa, a su llegada a la hacienda La Tinaja con Isabel Ilincheta, derriba a un esclavo anciano, por el solo hecho de que no corrió a abrirle el portón, aun cuando apenas podía caminar apoyándose en un bastón y,

[...] mientras montó a caballo y salvó la distancia que lo separaba de su intentada víctima, dio tiempo para que este se pusiera inconscientemente al amparo de las señoras. Pero al notar que se le venía encima a todo correr, y que gritaba: - ¡Ah, perro! ¡Ahora lo verás! No pudo desconocerle, ni dejar de caer de rodillas a los pies del caballo, quien conteniéndose y todo lo echó a rodar con el solo bote del pecho (Villaverde, I983, p. 52). 
La novela Cecilia Valdés es un referente obligado para estudiar la sociedad cubana del siglo XIX, en todos los aspectos de la vida social. $\mathrm{Su}$ personaje principal, Cecilia, es una joven fruto de los amores secretos de una mulata con un señor de sociedad de apellido Gamboa, que obliga a su madre a dejarla a ella en una casa cuna, de ahí que tenga el apellido Valdés. A pesar de estas contrastadas posiciones sociales, Cecilia, inculcada por su abuela, desprecia a los de su color y por tanto condición social «...y has de saber que blanco, aunque pobre, sirve para marido, negro o mulato, ni el buey de oro». Estas eran las palabras de su abuela y que Cecilia aprendería muy bien para expresar: «No lo niego, mucho sé que me gustan más los blancos que los pardos. Me moriría de vergüenza, si me casara y tuviera un hijo salto atrás».

Nadie, con la exactitud y la destreza de Cirilo Villaverde, pudo denunciar la realidad social cubana, casi de forma documental. La vida de los esclavos y la forma como eran mirados por una sociedad que ellos sostenían en el orden económico y ya para aquel entonces cultural (en una gran parte) y que en cambio los subyugaba. No solo eran despreciados y discriminados los esclavos, sino mulatos y negros libres. Estas relaciones de subordinación aparecieron en la novela como marco de referente social y base de la historia de los amores incestuosos entre Cecilia Valdés y su medio hermano Leonardo Gamboa. La historia, termina con el asesinato de Leonardo el día de su casamiento, pretexto de Cirilo Villaverde para establecer las relaciones enmarañadas y subordinadas de blancos y negros, libres y esclavos en la sociedad del siglo XIX cubano.

En el siglo XX aparecen otras obras de la literatura que expresan el tema de la esclavitud, como son los poemas y escritos de Nicolás Guillén, la novela Caniquí (1936) de José Antonio Ramos y El negrero de Lino Novas Calvo. Sin embargo, a nuestro juicio, el punto cimero le corresponde a Ekue-Yamba-O, del novelista Alejo Carpentier, publicada en Madrid en I933 y que según Ambrosio Fornet constituyó el punto de partida de $E l$ reino de este mundo. 
Ekue-Yamba-O aporta a los estudios de la sociedad cubana, la vida del negro en la República en los últimos años del machadato. Su concepción descansa en el trabajo intenso y la lucha desesperada de los negros por la subsistencia. En esta obra se habla del naciente latifundio, la insalubridad, la pobreza extrema, la ignorancia y el total desamparo ante los fenómenos naturales. Menegildo, personaje protagónico, encarna en sí el resultado de una clase social que ha cargado con el estigma de ser negra. Es Ekue-Yamba-O una novela rica en matices sobre la religiosidad popular, de antecedente africano y haitiano, lo cual se muestra en los primeros capítulos, haciendo referencia al encuentro de Menegildo con el mundo a su alrededor:

Pero de pronto, un maravilloso descubrimiento trocó su llanto por alborozo: desde una mesa baja lo espiaban unas estatuillas cubierta de oro y colorines. Había un anciano apuntalado por unas muletas, seguidos de dos canes con la lengua roja. Una mujer coronada, vestida de raso blanco, con un niño mofletudo entre los brazos. Un muñeco negro que blandía un hacha de hierro. Collares de cuentas verdes. Un panecillo atado con una cinta... (Carpentier, 1977, p. 22).

En esa obra, el autor narró en voz de uno de sus personajes, los maltratos que sufrían los africanos esclavizados en nuestras tierras, maltratos en los que la mente de los esclavistas y mayorales, enferma de poder y odio, se esmeró en diseñar:

Por cualquier cosa le meneaban el guarapo, jay niño! Silbaba la cáscara de vaca o el matanegro sobre las espaldas contraídas. El cuero y el bejuco levantaban salpicaduras de sangre hasta el techo del tumbandero [...] y a veces, cuando el delito era mayor, se aplicaba el "boca abajo llevando cuenta" y el supliciado tenía que contar en voz alta los azotes que recibía. Y si se equivocaba, ¡ay niño! El mayoral empezaba de nuevo. ¿Quién comprendía que muchos bozales traídos por la fuerza desde África directamente, sin hablar español, solo sabían contar hasta 250 
30? Nadie. Los gritos desgarraban la garganta [...] y después para curar las heridas, le untaban con una mezcla de orina, aguardiente y sal (Carpentier, I977, p. 22).

Sobre los encuentros de los domingos en los cabildos de nación y la percepción que tenían de la celebración del día de reyes, afirma:

Sólo los domingos, después de la limpieza del batey y de la casa vivienda, la dotación podía olvidar sus padecimientos durante unas horas. Bajo la presidencia del rey y de la reina designados para la ocasión, el bastonero daba la señal del baile. Retumbaban los tambores, y los cantos evocaban misterios y grandezas de allá... Pero las negradas del campo ignoraban los esplendores de la Fiesta de Reyes, que sólo se celebraba dignamente en las ciudades. Ese día las calles eran invadidas por comparsas lucumíes, de congos y ararás, dirigidas por diablitos, peludos, reyes moros y "culonas" con cornamentas (Carpentier, I977, p. 23).

Más adelante en el mismo capítulo cuenta:

Pero estos fugaces holgorios no compensaban una infinita gama de sufrimientos. El negro que no moría por enfermedad o a causa de un castigo, acababa pegado a una talanquera, hecho hueso y pelo... Los mayorales eran la plaga peor. Abusadores, crueles, altaneros. Doblando siempre el espinazo ante el amo, descargaban sus secretos rencores sobre el siervo de carne obscura (Carpentier, I977, p. 23).

Aunque Alejo Carpentier manifestó que, de sus novelas, la menos preferida por él era Ekue-Yamba-O. Estamos ante una obra que logra, de manera brillante, la caracterización del hombre negro en los primeros años de la República. El autor, a la vez que describe la ignorancia del seno familiar de Menegildo y los temores ocasionados por esta sumisión, desarrolla un estudio abarcador de la cultura popular de este 
período de tiempo: la de los desposeídos y los marginados que buscan, en la propia simbología que los rodea, las respuestas a procesos y fenómenos de todo tipo que se ven obligados a enfrentar. En esta lucha entran en pugnas y contradicciones propias de la alienación y marginalidad a las que la sociedad los ha relegado. Esta novela fue publicada en la segunda década después del triunfo de la Revolución Cubana y en ella se ve, al final de la misma, la posición del autor a favor del nuevo proyecto social, en la voz del narrador que trazará los destinos de otra generación que ha nacido después de 1959.

La literatura ha sido rica en matices. No solo ha recreado el fenómeno de la esclavitud y la vida de los africanos y sus descendientes, sino que se ha detenido en sus costumbres, religión y en la forma como salvaguardaron el andamiaje cultural traído de sus tierras. Es de analizar el hecho de la supervivencia de las religiones de origen africano en las condiciones actuales, teniendo en cuenta que solo contaron para protegerlas con sus prácticas, en la mayoría de los casos secretas, con la oralidad, lo que fueron contando de una generación a otra. Apenas se dieron algunos testimonios por parte de importantes investigadoras como Natalia Bolívar y Lidia Cabrera, de libretas de religiosos que constituyeron aportes valiosísimos de sus prácticas, lo demás fue oral. A ello súmesele el desprecio en los primeros años de la República hacia la herencia africana y la política blanquedora que exaltó otros valores de la cultura e intentó borrar la huella del negro en la cultura cubana. Según Argeliers León:

Se pasaba por un movimiento de guajirismo, en el que estaban muy interesadas las clases dominantes, con lo cual se tapaba el bochorno, de la esclavitud del negro y se buscaba un prototipo de lo cubano lo suficientemente limpio de aquel antecedente (León, I98I, p. 95).

Sin embargo, la historia les tendría reservado un lugar imperecedero. Los africanos y sus descendientes protegieron con celo sus prácticas, resguardaron y cultivaron sus memorias. Reprodujeron su mundo 
perdido en África en lo que encontraron en este suelo desconocido para ellos. La necesidad y el desamparo hizo que en las deidades del santoral católico encontraran a sus orichas, los asociaban según los símbolos, las historias, los colores. Este es un tema muy discutido en la cultura cubana, teniendo en cuenta la polémica de si realmente hubo sincretismo o no.

En Cuba, bautizada por el sabio Fernando Ortiz, como un gran ajiaco cultural, estas prácticas se fundieron y expresaron nuevos sistemas religiosos que caracterizan e identifican nuestra religiosidad popular. La creación de los cabildos fue un hecho trascendente que contribuyó a la perdurabilidad de la huella africana en la cultura cubana.

Los esclavistas del sur americano se diferenciaron de los del norte, en que los primeros permitieron la presencia de los cabildos, no por gestos filantrópicos, sino porque sencillamente lo permitieron. En estos cabildos se reunían los esclavos de una misma nación y realizaban sus prácticas religiosas y culturales.

A lo largo del país, persisten estos cabildos, con más de un siglo de creados. En la política cultural de la Revolución, estas prácticas son protegidas y forman parte del patrimonio cultural de la nación. Uno de los más significativos, es el de la denominación Kukanga, ubicado en Lajas, municipio de Cienfuegos. Allí todavía se conservan cantos en las lenguas originarias. Se distingue por una historia muy peculiar. A dos casas de él nació y creció Beny Moré, el Bárbaro del Ritmo, por lo que su niñez estuvo vinculada a este lugar, incluso cuando murió se le realizó una ceremonia en el cabildo. Lo más llamativo es la utilización de la bandera cubana. Se realiza una danza donde un abanderado pasea bailando con la insignia por todo el salón, como una muestra de la cubanía presente en estas prácticas religioso-danzarias. Lo anterior es solo una muestra de cómo las prácticas culturales y religiosas de origen africano consolidaron la historia y la cultura cubana. Nada describe mejor nuestra herencia y permanencia africana, que el poeta Nicolás Guillén, cuya obra aparece estudiada por la autora Denia García Ronda 
en el volumen ¡Aquí estamos!, El negro en la obra guilleniana, de donde tomamos como epílogo el siguiente poema:

En esta tierra, mulata de africano y español (Santa Bárbara de un lado del otro lado, Changó), siempre falta algún abuelo, cuando no sobra algún Don y hay títulos de Castilla con parientes de Bondó: vale más callarse, amigos, y no menear la cuestión, porque venimos de lejos y andamos de dos en dos. Aquí el que más fino sea, responde si llamo yo (García, 20I7, p. 9).

\section{Referencias}

Avilés, P. (2020). De la esclavitud al trabajo asalariado. España: Akal.

Barnet, M. (20I6). Biografía de un cimarrón. La Habana: Letras Cubanas. Barnet, M. (20II). La fuente viva. La Habana: Casa Editora Abril.

Beecher Stowe, H. (1973). La Cabaña del Tio Tom. Londres: Editorial Wessen.

Bueno, S. (I988). La narrativa antiesclavista en Cuba de I835 a I839. Cuadernos Hispanoamericasnos, (45I-452), I69-I86. Recuperado de: http://www.cervantesvirtual.com/obra/la-narrativaantiesclavista-en-cuba-de-I835-a-I839/

Carpentier, A. (1977). Ekue-Yamba-O. La Habana: Editorial Arte y Literatura.

Castro, A. (2015). Juan Francisco Manzano, Autobiografía. Matanzas: Ediciones Matanzas.

Cue Fernández, D. (2007). Plácido, el poeta conspirador. Santiago de Cuba: Editorial Oriente. 
Lara, O. (2004). La esclavitud y sus modalidades. Recuperado de: http:/www.culturaclasica.com/nuntii2004/febrero/esclavitud.h tm

Manzano, F. (2015). Autobiografía. Matanzas: Ediciones Matanzas.

Galeano, E. (2004). Las venas abiertas de América Latina. La Habana: Editorial Casa de las Américas.

García Gómez, D. (2013). Antecedentes de la esclavitud americana: el mundo hispano. Estudios afroamericanos. Biblioteca virtual. Fundación Fernando Ortiz.

García Ronda, D. (20I5). Presencia negra en la cultura cubana. La Habana: Ediciones Sensemayá,

García Ronda, D. (20I7). jAquí estamos! El negro en la obra guilleniana. La Habana: Ediciones Sensemayá.

Gómez de Avellaneda, G. (2000). Antología. Novelas y ensayo. Sab, Dos mujeres, Dolores, El cacique de Turmequé, La mujer. Madrid: Fundación José Antonio de Castro.

Guillén, N. (2002). Obra Poética. La Habana: Letras Cubanas.

Guanche, J. (2009). Africanía y etnicidad en Cuba. La Habana: Editorial de Ciencias Sociales.

Guanche, J. (20II). Componentes étnicos de la nación cubana. La Habana: Editorial de Ciencias Sociales.

León, A. (198I). Del canto y del tiempo. La Habana: Editorial Pueblo y Educación.

Manzano, F. (20I5). Autobiografía [Edición Facsimilar y anotada por Alex Castro]. Matanzas: Ediciones Matanzas.

Martínez Carmenate, U. (2009). Domingo del Monte y su tiempo. Matanzas: Ediciones Matanzas.

Morgan, K. (20I7). Cuatro siglos de esclavitud trasatlántica. España: Editorial Planeta.

128 Moulier Boutang, Y. (20I7). De la esclavitud al trabajo asalariado, España: Ediciones Akal.

Ortiz, Fernando. (1963) Del fenómeno social de la transcilturación y su importancia para Cuba, en Contrapunteo cubano del tabaco y el azúcar. La Habana: Consejo Nacional de Cultura. 
Pérez, E., y Lueiro, M. (2009). Raza y racismo. La Habana: Editorial Caminos.

Rediker, M. (20I4). El barco de esclavos. La Habana: Ediciones Imagen Contemporánea.

Rubiera Castillo, D. (20II). Reyita, sencillamente. Testimonio de una negra cubana nonagenaria. La Habana: Fondo Editorial Casa de las Américas.

Sosa, E. (1978). La economía en la novela cubana del siglo XIX. La Habana: Editorial Letras Cubanas.

Villaverde, C. (1983). Cecilia Valdés o la Loma del Ángel (tomo II). La Habana: Instituto Cubano del Libro.

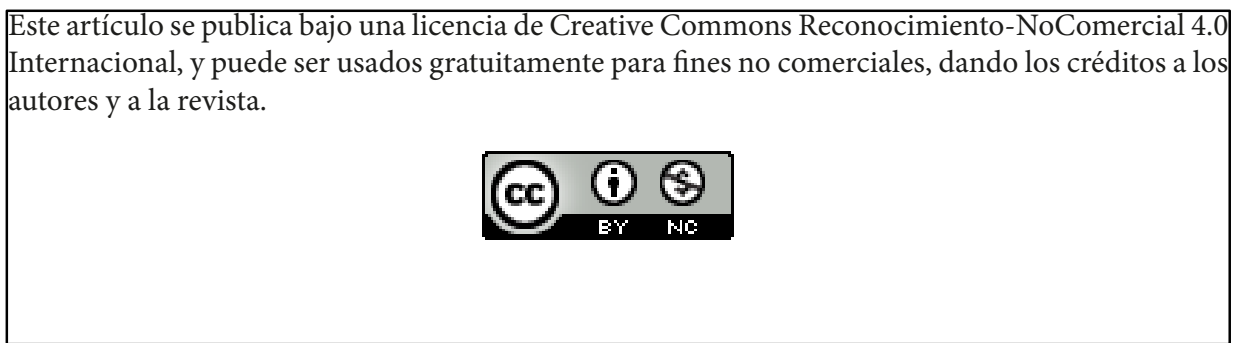

